\title{
How to remove nose skin excess? Aesthetically reasonable approach
}

\author{
M. Sulamanidze*, G.Sulamanidze, and K. Sulamanidze \\ Clinic of Plastic and Aesthetic Surgery TOTALSHARM, Tbilisi, Moscow
}

\begin{abstract}
Aesthetic correction of a big nose, especially in the case of thick spongy skin, is always connected with some difficulties, because of unpredictable results of the corrective intervention.

Purpose: To present open rhinoplasty technique modification when we remove nose skin excess with post-operative cicatrices in barely visible places.

Material and methods: The main techniques that we used while performing aesthetic rhinoplasty, with excision of skin excess included, were the following:

1. Original marking of the surgical intervention area.

2. Incisions and extensive mobilization of the nose cutaneous covering.

3. Necessary correction of the nose base support structures, especially of the nasal tip and nose wings.

4. Excess nose skin removal, with post-operative cicatrices in barely visible places.

Results: We have used this surgery technique since 2002 in 48 cases. Mostly the results obtained were characterized as good and satisfactory.

Conclusions: The mentioned modification of open rhinoplasty can be effective in the case of rhinomegaly, when there is a sufficient excess of thick porous skin and rounded or long nasal tip and nostrils.
\end{abstract}

\section{Introduction}

From a large variety of external nose aesthetic deformations, big noses with thick porous skin are always operated on very unwillingly even by experienced rhinologists [1-9].

\section{Here are the reasons}

Thick porous skin does not contract properly during the postoperative period. It does not conform to the position of the support frameworks. That is why the nose often takes shapeless contours (Figure 1).

Cutaneous covering excess on the nasal tip, nasal arch, lateral nasal walls, and wings of the nose, that sometimes appear after the nose support structures reduction, should be excised. However, today only the method of shortening the nose length and decreasing of the nasal wings convexity with post-operative cicatrices in barely visible places is offered. It is not always enough for getting good results. And aesthetically admissible ways of excess skin removal from the other parts of the nose do not exist. Surgeons have to perform skin resections in visible parts of the nose (Figures 2, 2a, and 2b) [1-5]. These methods do not have their followers because of the possibility of getting postoperative cicatrices on the aesthetically important nose parts. We either have never practiced such incisions or skin resections during rhinoplasty, although we often have faced the necessity of using them [6].

For that very reason in 2002 we developed such a modification of rhinoplasty that enabled us to excise skin excess using incisions in barely visible parts of the nose [7-9].

\section{The purpose}

The purpose is to present the method of excess nose skin removal from the nose during rhinoplasty, that could make it possible "to hide" post-operative cicatrices in barely visible places. Meanwhile, we focused our attention on the noses that were supposed to get reduction

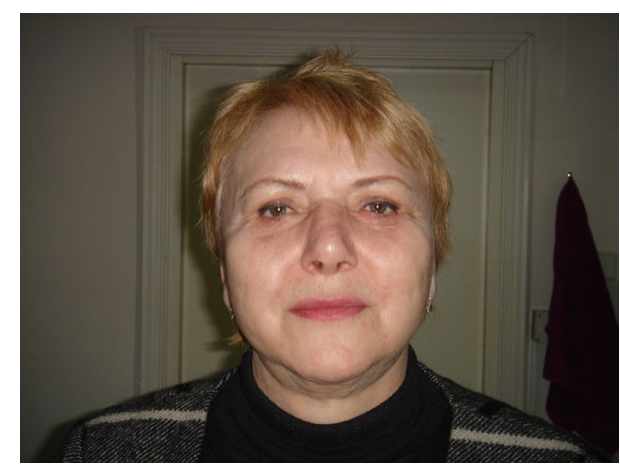

Figure 1. The case of complications after close rhinoplasty that happened while operating on the patient with a thick, porous skin - shapeless nasal tip, dimension mismatch of the cartilaginous stractures and skin.

Correspondence to: Dr. Marlen Sulamanidze, Plastic and Reconstructive Surgery, Clinic “Total Charm” Tbilisi, Georgia, Tel: +995 5953220 20; E-mail: gracia@aptos.ru

Key words: rhinoplasty, rhinomegaly, big nose, nose skin excess

Received: April 18, 2016; Accepted: May 22, 2016; Published: May 27, 2016 

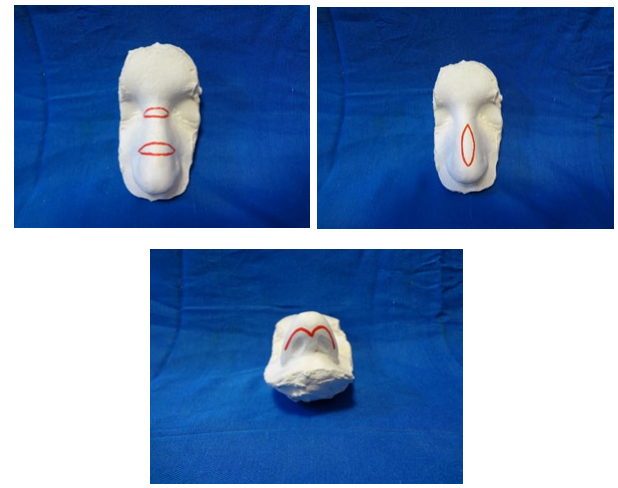

Figure 2a, 2b. Plaster casts on which you can see incision marking for excess skin excisions - classical variants.

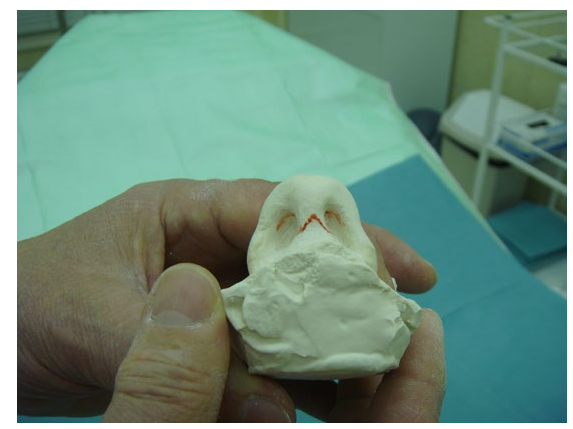

Figure 3. Presurgical marking on the plaster cast for the patients of group I.

of the nasal tip skin area, supratip area, nose wings, and also shortening of the nostrils' height. In this work we do not consider patients with great width in the base, but low in the nasal tip noses, as well as noses that had wide nostrils.

\section{Materials and methods}

48 cases of rhinoplasty were analyzed. In these cases we performed excision of skin excess in accordance with our method. We performed this number of surgeries from February, 2003 till May, 2012, which is $8 \%$ of all the interventions concerning aesthetic deformations of the nose shape. The age of the patients was ranged from 20 to 48 years old. There were 37 women and 11 men.

The patients were divided into 3 groups, based on the difference in the volume of excess skin removal during the surgeries:

1. Patients who needed reduction of skin excess only from the nasal tip that could be attained by its excision in the columella area (19 persons - 39\%).

2. Patients who needed skin excess reduction separately from the nose tip and separately from the nose wings (21 persons - 43\%).

3. Patients who needed total nose skin excess reduction (8 persons - 18\%).

\section{Description of the surgery techniques}

\section{Surgery technique for the patients of group I}

Regular surgery marking, as for open rhinoplasty (Figure 3). We performed the incision in accordance with the marking: along the cutaneous part of the columella, then along its lateral surface upwards to the cupula and then along the internal surface of the wing. We made a similar incision on the other side of the nose. We mobilized the cutaneous covering of the nasal tip and partially of the wings, made surgical manipulations on the osseo-cartilaginous structures, and, in cases of necessity, on the inside of cellulocutaneous flap, hemostasis (Figure 4). After that we pulled the margins of the flap downwards to the columella, excised the skin excess and sutured the edges of the wound using interrupted stitches. Meanwhile, first it is important to cut the top edge of the wound of the columella in three places - one cut is in the middle part and the two of the others are at the both end (Figure 4a). The length of the skin cuts depended on the quantity of the cutaneous covering that was supposed to be excised. The cuts bases and the inferior edge of the wound were sutured using guiding iterrupted stitches. The skin excisions were made sequentially from the left and right sides between the sutures, in separate pieces that had the same shape and size. Then the wound was finally closed.

Thus, the only difference between this surgery technique and the well-known technique of "open" rhinoplasty is that we can make additional excisions of skin excess in the area of the columella, if necessary.

It is necessary to attract your attention to the fact that the methods of columella skin excision had been offered earlier, but it was recommended in order to improve cicatrix aesthetics after a failed open rhinoplasty [10].

\section{Surgery technique for the patients of group II}

The marking and the appropriate surgery were performed according to the the technique mentioned above. But we also made classical excisions of semilunar pieces of the skin at the base of the nose wings. The last action was necessary for the length and convexity reduction of the wings (Figure 5).

\section{Surgery technique for the patients of group III (please, watch our video).}

Marking (Figure 6), and the incision were made in the same way

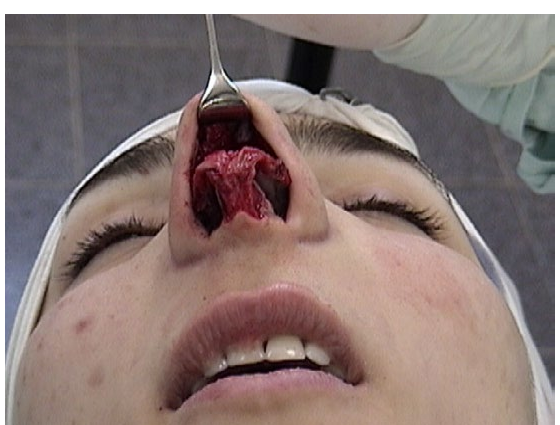

Figure 4. Mobilization of the nasal tip cutaneous covering.

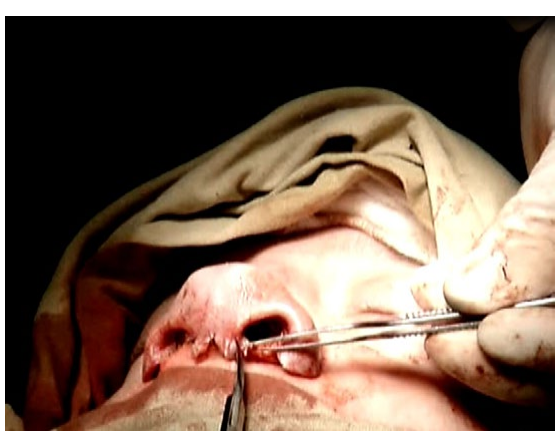

Figure 4a. Dissection of the top edge of the columella wound in 3 places. 


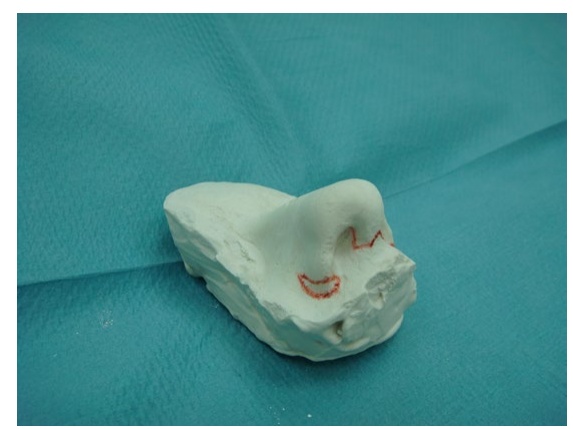

Figure 5. Presurgical marking on the plaster cast for the patients of group II

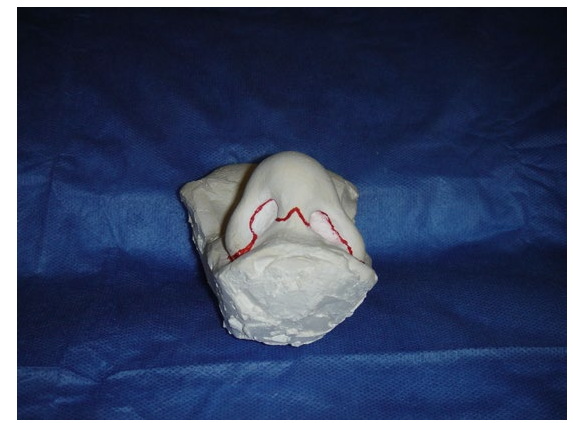

Figure 6. Presurgical marking on the plaster cast for the patients of group III.

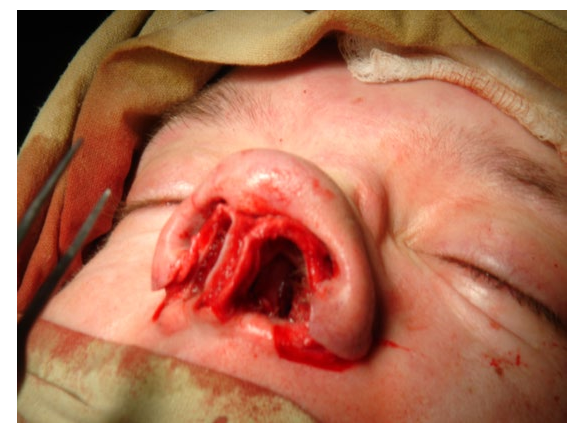

Figure 6a. Mobilization of the nasal tip cutaneous covering, wings and other parts of the nose.

as during the surgery for the patients of group I, but later the incision was prolonged downwards along the interior wing side to its base. We "went" round the front edge of the base and "came" to the skin surface of the wing along the lines of the fold. The incision ended in the place where the fold of the wing base ended, that is at the border of the lateral nasal wall. We made a whole block mobilization of the cutaneous covering of the necessary size - nasal tip, nose wings, nasal arch, and lateral nasal walls (Figure 6a). Also we made surgical manipulations on the osseo-cartilaginous and the other structures, their correction, and hemostasis. In the cases of necessity, we made thinning of cellulocutaneous flap from the internal surface side. After that we pulled the margins of the flap downwards to the columella and laterally to the wings. The excess skin excisions in the columella area were made in the same way as during the surgeries for the patients of group I - with a preliminary dissection of the top edge of the wound and putting guiding interrupted sutures. The same dissections and wound closures were made in the cupula area, the wings internal surface area, and also outside at their base - 3-5 pieces on each side (Figure $6 \mathrm{~b}$ ). Skin excisions were made sequentially from the left and right sides between the sutures, in separate pieces that had the same shape and size. And only after that the wound was finally closed (Figure 6c).

Thus, post-operative stitches were put in the parts that were typical for open rhinoplasty surgery: in the columella area, cupula area, nose vestibule area, and also along the folds at the bottom of the wings. That is why the stitches were barely visible (Figures $6 \mathrm{~d}$ and 6e).

It should be noted that the direction and dimensions of the incisions, used in this case, and the great length of the flap mobilization

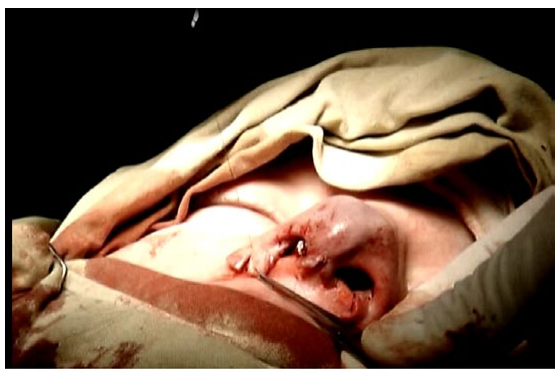

Figure 6b. Dissection of the top edge of the wound of the wing.

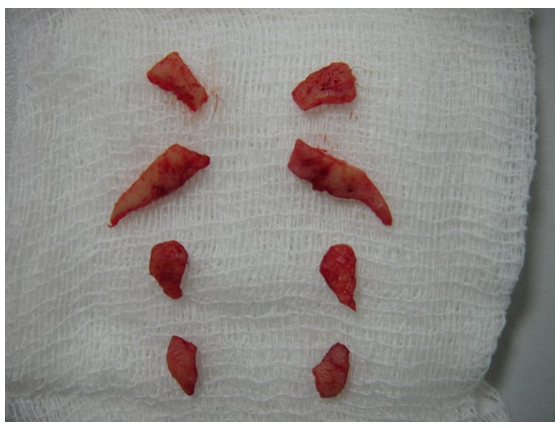

Figure 6c. Excessskin flaps.

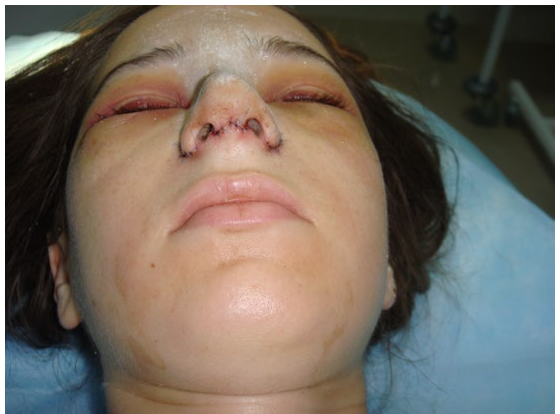

Figure 6d. Postoperative stitches (the photo made in 2 days after the surgery).

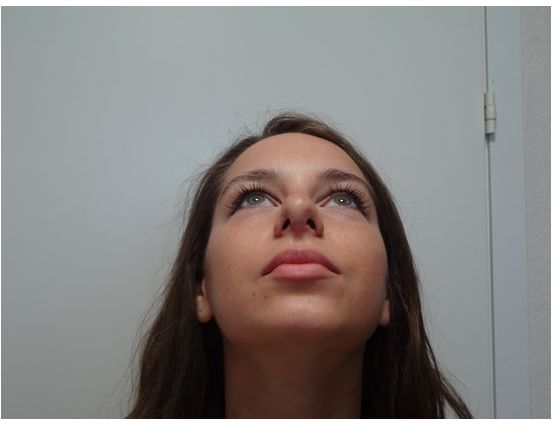

Figure 6e. The result in 1 year after the surgery, bottom view. 
did not cause any concern that the flap edges would fall in necrosis. The safety of this approach was demonstrated by our colleagues in their earlier publications $[11,12]$.

\section{Results}

The technique of intervention, described above, was developed specially for excision of a great nose skin excess (patients of group III). The first surgeries were performed precisely in such cases (Figures 7

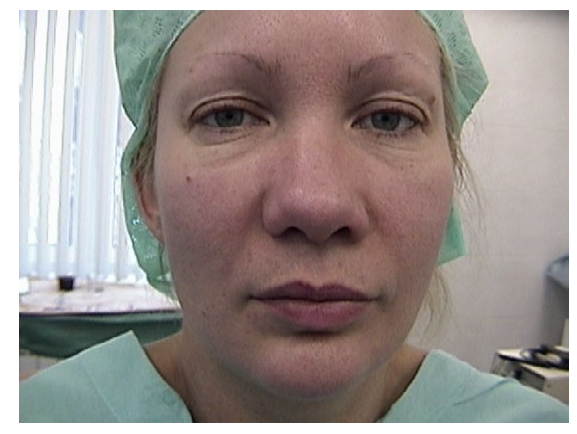

Figure 7. Patient E..., 42 years old; she has a big "pineal" nasal tip, a nose with wide rounded wings and thick, porous skin, full face view (group III). Before the surgery.

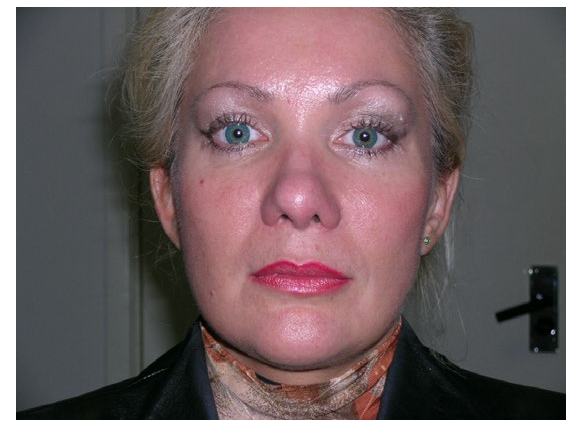

Figure 7a. See fig.7. In 2 years.

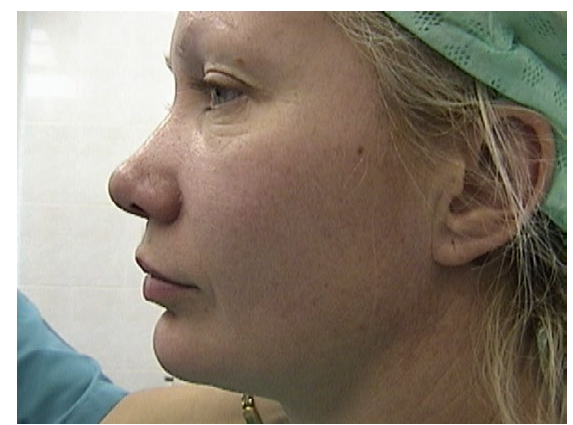

Figure 7b. See fig.7, before, profile view.

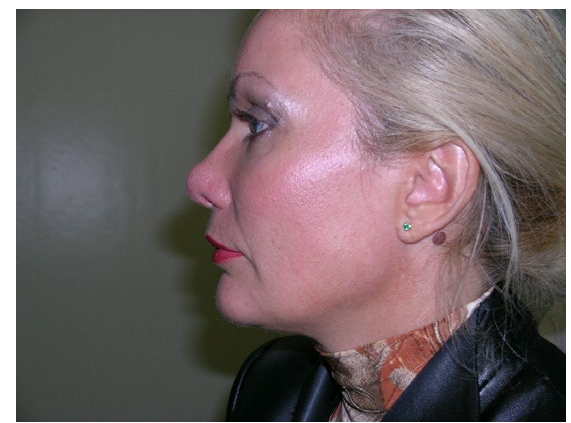

Figure 7c. See fig.7. In 2 years. and 8). Nonetheless, subsequently we noticed that when we performed the surgeries of classical open rhinoplasty sometimes while matching the wound edges on the columella, some skin excess appeared. Our observations showed that those were patients with bigger "pineal" or "duck" nasal tips, who had skin excess as a result of cartilaginous base reduction of the nasal tip at the end of the surgery. That is why an idea of excess skin excision only from the columella area came to our minds.

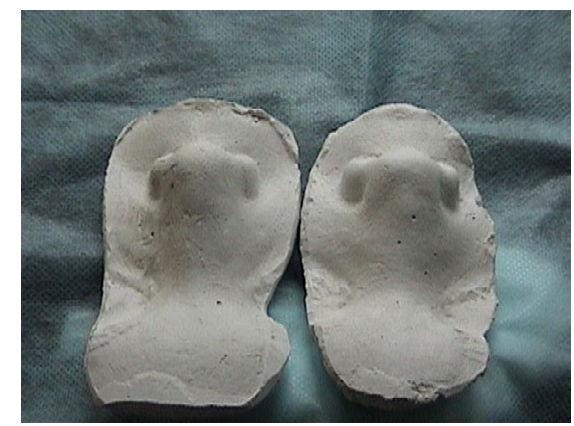

Figure 7d. Plaster casts of patient E's... nose: on the right - before, on the left - in 2 years.

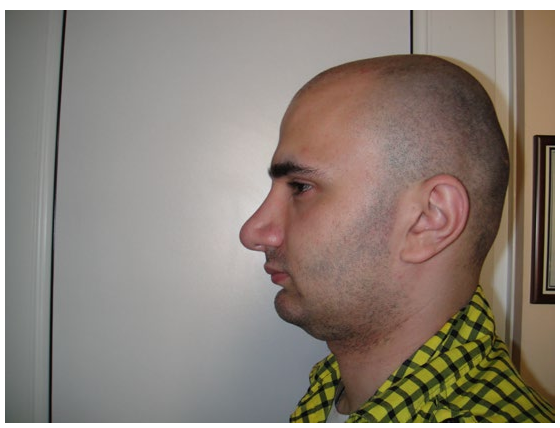

Figure 8. Patient L..., 24 years old, was operated on in some other clinic 1 year ago. His nose is big (tip, wings). He has thick, porous skin - profile view (group III).

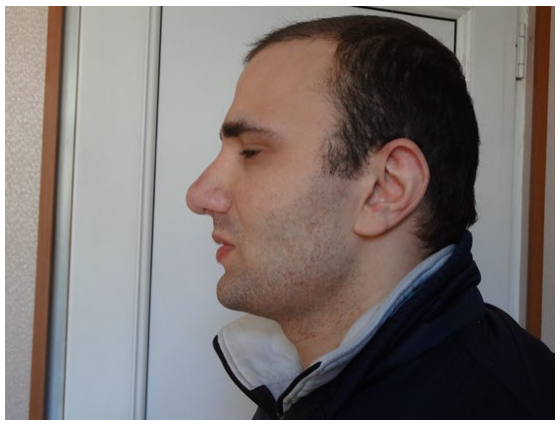

Figure 8a. See fig 8. In 2 years and 3 months.

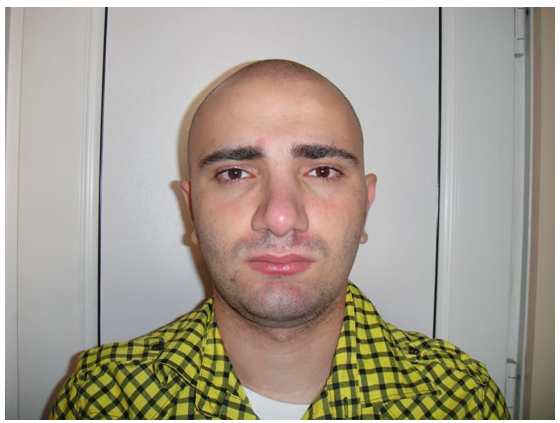

Figure 8b. See fig 8. Full face view. 
Having performed several of such surgeries (group I), we noticed a positive influence of this technique on the surgery results - the skin on the tip was tightly pressed towards the underlying structures and survived faster (Figures 9 and 10).

The next stage involved performing of such surgeries of rhinoplasty that required combined excess skin excision in the columella area and semilunar flaps of wings base skin (group II). The results of the surgeries performed in the way described above were also good (Figure 11).

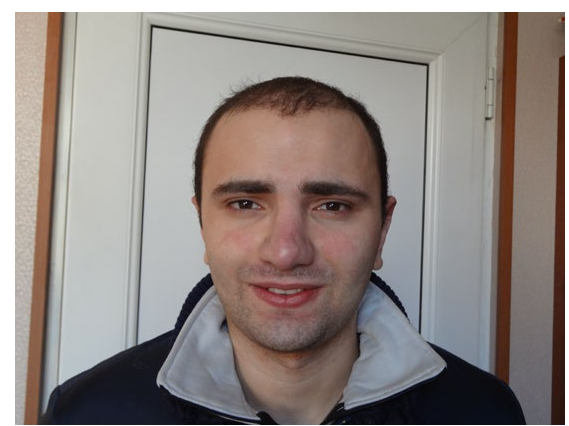

Figure 8c. See fig 8. In 2 years and 3 months.

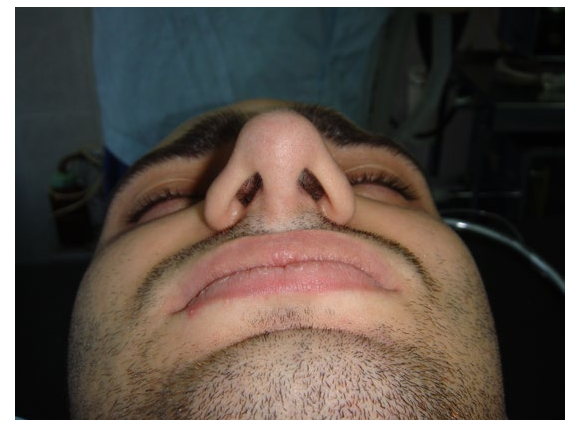

Figure 8d. See fig 8. Bottom view.

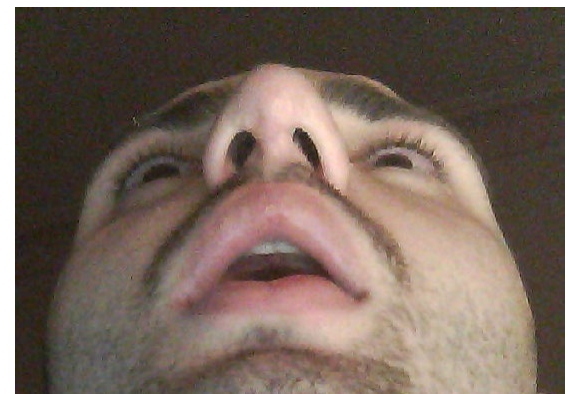

Figure 8e. In 2 years and 3 months.

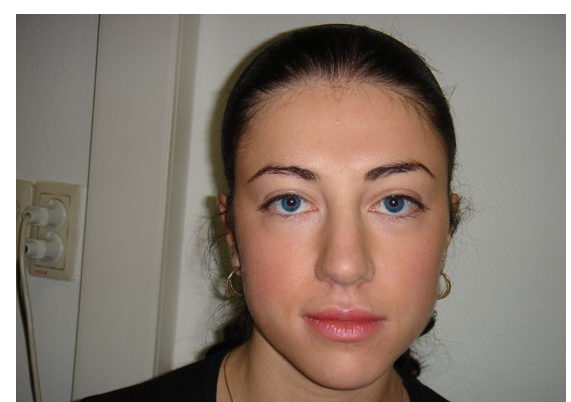

Figure 9. Patient I...22 years old. She has a big nasal tip, apparent lateral limbs of wing cartilages, full face view (group I).

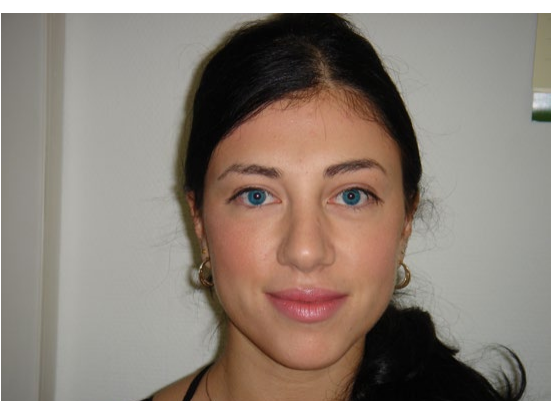

Figure 9a. See fig 9. In 1 year and 2 months.

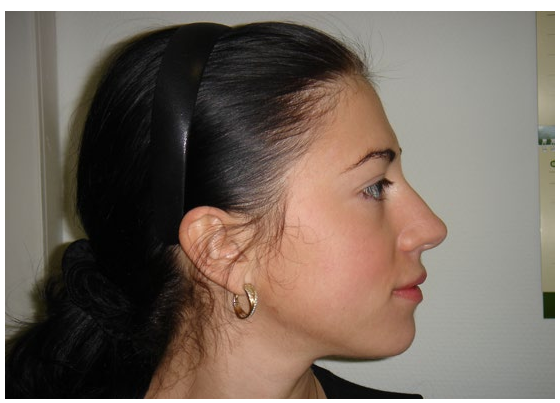

Figure 9b. See fig 9. Full face view, before the surgery.

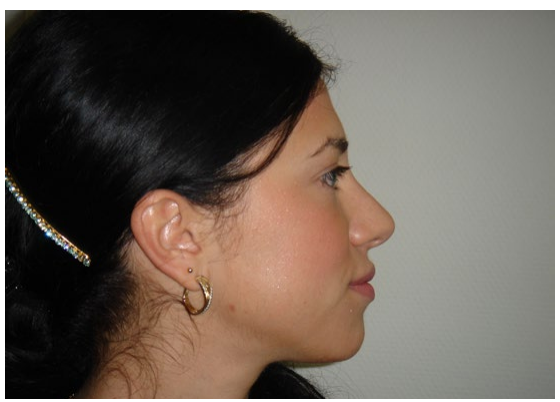

Figure 9c. See fig 9. In 1 year and 2 months.

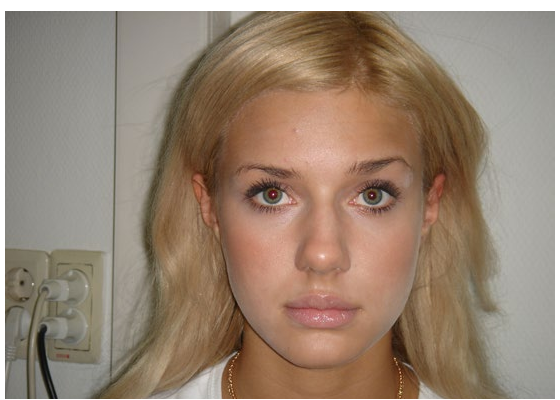

Figure 10. Patient R... 20 years old, before the surgery. She has a big "pineal" nasal tip, full face view (group I).

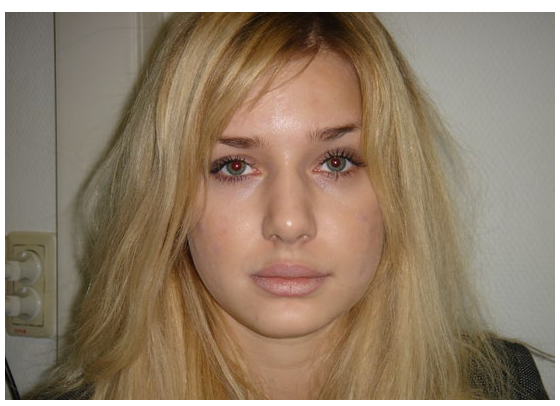

Figure 10a. See fig 10. In 1 year. 


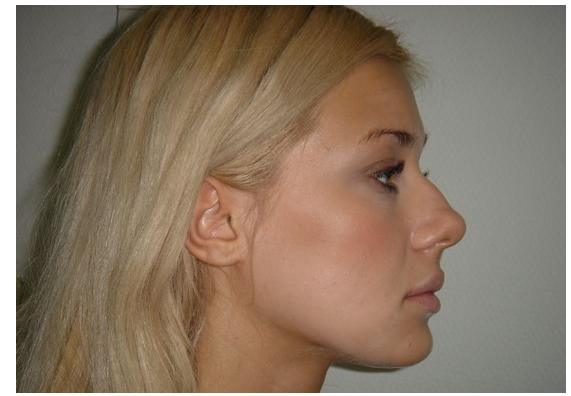

Figure 10b. See fig 10. Profile, before the surgery.

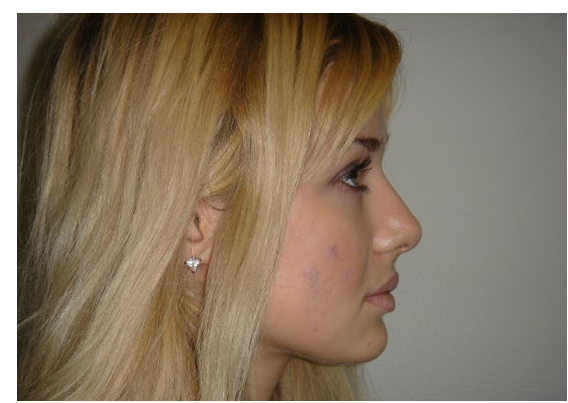

Figure 10c. See fig 10. In 1 year.

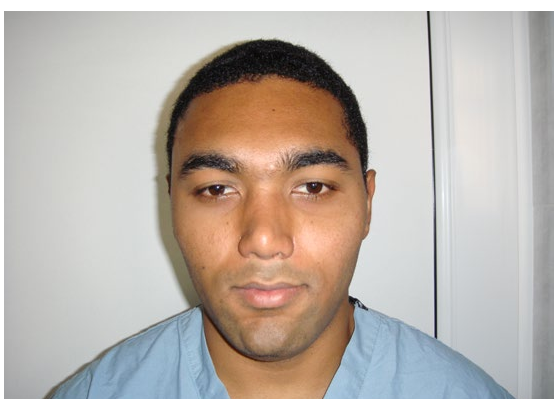

Figure 11. Patient D..., 26 years old, was operated on in some other country. His nose is big (nasal tip, wings). He has a low wide nasal arch, full face view (group II).

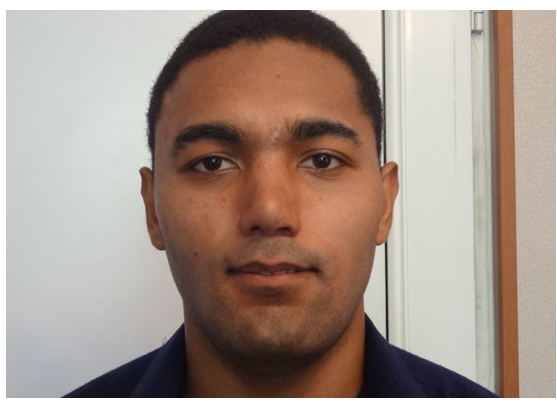

Figure 11a. See fig 11. In 1 year and 6 months.

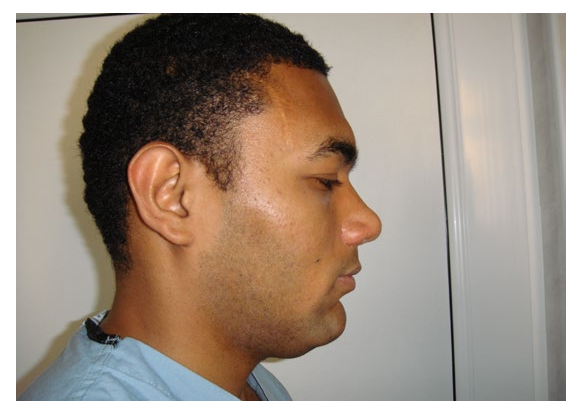

Figure 11b. See fig 11. Left profile view, before the surgery.

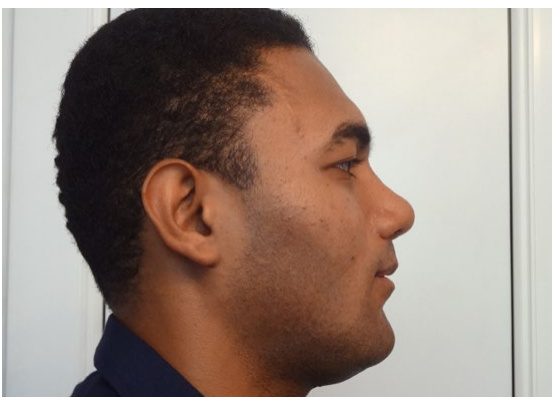

Figure 11c. See fig 11. In 1 year and 6 months.

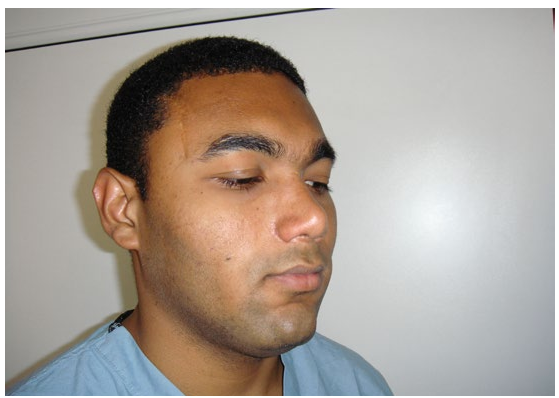

Figure 11d. See fig 11. Left half profile view.

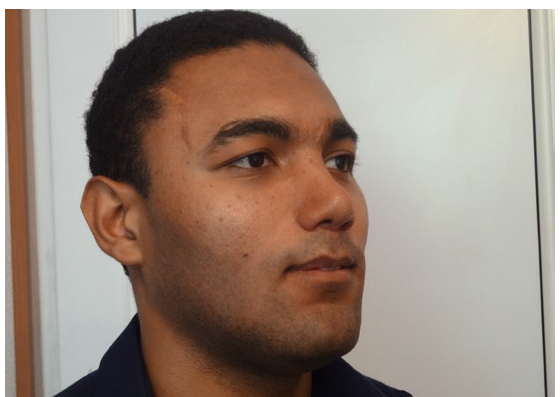

Figure 11e. See fig 11. In 1 year and 6 months.

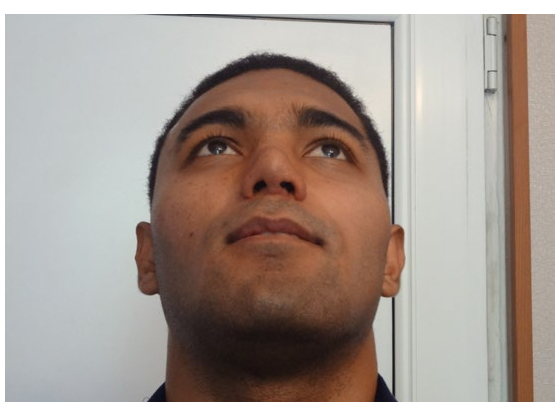

Figure 11f. See fig 11. Bottom view. In 1 year and 6 months.

During our practice we often have had the necessity of nostrils' height and width reduction. Sometimes it was necessary for a oneside reduction of a nostril. The technique mentioned above allowed us to "shorten" nostrils and attain a good effect with cicatrices in barely visible parts of the nose (Figures 12 and 12a).

\section{Discussion}

Experienced rhinologists determine the presence of nose skin excess even at the first examination of the patient and prognose its appearance while performing a rhinoplasty surgery. Therefore they decide in advance which technique of intervention to use. They usually 


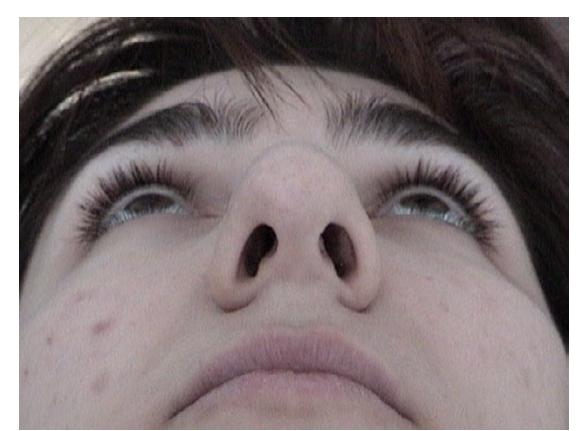

Figure 12. Patient D-a, 29 years old. Nose with long rounded wings, big prolonged nostrils, bottom view (group III).

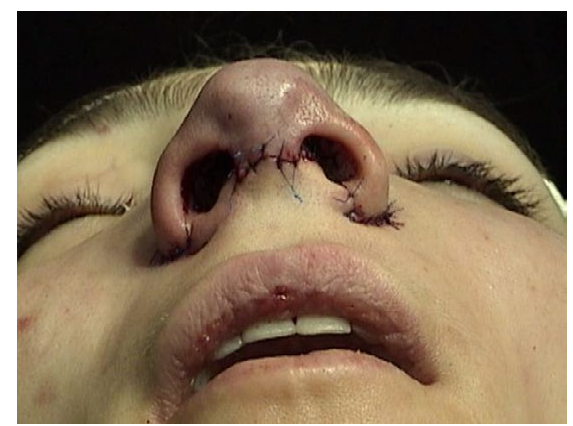

Figure 12a. See fig 12. Immediately after the surgery.

have a choice of performing flap excisions of the skin from the nasal arch or from the nasal tip (horizontal, vertical, figured) or perform only classical rhinoplasty without excess skin excisions and "wait" (often in vain) for its area reduction in the post-operative period. The patient's opinion in choosing one of the techniques plays an important part. He/she can decline both the possibility of getting a post-operative cicatrix in a visible part of the nose, and the necessity of waiting for a final result during several months. We used to reject such patients and recommended them to accept their aesthetic nose deformation.

The developed technique mentioned above made it possible for us to solve these problems: as a result we could help patients with big noses with thick spongy skin. We think that this technique is successful due to the following two factors: a) excision successfulness of the required skin quantity during the operation, $b$ ) invisibility or visibility of postoperative cicatrices. At the beginning of this technique testing and later, during experience accumulation, we were completely aware that such a technique would not allow us to make an exquisite nose shape like in the cases of noses with thin skin, because the structure, thickness, and skin colour of the nose would not change. Only skin area would reduce. Therefore we consider it improper to compare post-operative results at rhinomegaly with a thick porous skin and a "Caucasian" nose with a slight convexity and thin skin.

As in our practice we have never used modifications of rhinoplasty with skin excisions proposed earlier, we cannot show you any comparison of the results with the use of this method and other similar methods. We can only show two cases when patients with bigger noses were operated on using classical method of rhinoplasty in other clinics. After a while they were re-operated on in our clinic with the help of our technique. Such cases can show how successful our technique is:

\section{Case 1}

Patient L.., 24 years old, was operated on in some other clinic 1 year ago. When he came to our clinic we could notice a big nose, prominent nasal tip, big wings, thick, porous skin, and cicatrix on the columella typical for open rhinoplasty (Figures $8,8 \mathrm{~b}, 8 \mathrm{~d}$ ). From the anamnesis we could see that his nose had been bigger before the first surgery, but the surgeon had not made it small enough. That is why the patient did not like the result. We supposed that the previous surgeons had used classical open rhinoplasty without excess skin excisions. Therefore, while reoperating the patient we used rhinoplasty according to the type III (excess skin excisions in the columella area, in the cupula area, in the wings internal and external surfaces area) with a correction of the osseo-cartilaginous base of the nose. The postoperative period passed without complications. The final nose shape satisfied both the patient and the surgeons (Figures $8 \mathrm{a}, 8 \mathrm{c}$, and $8 \mathrm{e}$ ).

\section{Case 2}

Patient D..., 26 years old, was operated on in some other country a year and 6 months ago. When he came to our clinic we could notice a big nose with thick porous skin, deformed nasal tip, convex wings, low and wide nasal arch, typical cicatrices at the bottom of the wings of the nose and in the nose vestibule area (Figures 9, 9b, and 9d). We suppose that those were results of close rhinoplasty with excision of semilunar pieces of skin at the bottom of the wings. In our clinic we used open rhinoplasty: correction of the lateral limbs of the wing cartilages, osseous part of the nasal arch and lateral surfaces, and also excision of the semilunar of skin areas at the bottom of the wings. During the wound edges adaptation excess skin appeared on the columella. It was excised according to our technique. Thus, the surgery was performed according to type II (Figures 9a, 9c, and 9e). The final result was good.

Surgeons in other clinics refused to make rhinoplasty to most of our first patients that we operated on according to the technique (group III and partially group II), or did not guarantee a satisfactory result due to the skin excess and because their skin was quite thick and porous. That is why after our intervention they were pleased with the result. Complications that we were concerned about because of the dimensions of the incisions and great length of the flap mobilization did not arise. We did not make radical resections of cartilages. We also excised a moderate amount of hypodermic soft tissues. Mucosa integrity was not changed. That is why after quite a long period of time of the post-operative period our patients did not have problems with breathing in any case.

We excised a great amount of skin in the cases of the patients of group III (Figures 6c), moderate amount of skin in the cases of the patients of group II and small quantity of skin in the cases of the patients of group I. Skin excisions were performed in such a way that post-operative cicatrices were left on the skin of the columella, on the folds of the nose wings and intranasally - on the border of the skin and nasal mucosa. The wounds healed over by the primary intention, without hypertrophy and deformation of cicatrices. Therefore nasal passage constriction did not happen.

\section{Conclusion}

The described modification of open rhinoplasty can be effective in cases when the prediction of nose skin reduce during the postoperative period is doubtful (because of the advanced age, thick and porous skin), or initially there is an apparent skin excess, and we know about the necessity of its excising during the surgery. In this case, it is possible to plan quite a lot of excess skin excision, thus, postoperative cicatrices will be left in the barely visible parts of the nose. 
This technique also can be successfully used for correction of noses with big, long or asymmetrical nostrils, for the purpose of making them lower. Obviously, the described modifications of rhinoplasty can be used also for correction of a "prominent" nose and also for "parrot beak" deformation corrections.

\section{References}

1. Aiach GC, Kelly MH (2005) Secondary Rhinoplasty. The art of Aesthetic Surgery Principles and Techniques. Editor: Foad Nachai. Inc. St. Louis, Missouri. 1618-1676.

2. Ezrohin VM, Nikitin AA (1996) Surgical methods of correction of the nose with thick porous skin. Russian Rhinology N1. 60-63.

3. Fuleihan NS, Webster RC, Smith RC (2008) Deformity of the Nasal Base. Aesthetic Facial Surgery. Editor: Norman Pastorek. Lippincott 289-310.

4. Larrabee WF (2008) Rhinoplasty in the Aging Patient. Aesthetic Facial Surgery, Editor: Norman Pastorek. Lippincott 361-384.

5. Marchac D, Arnaud E (2011) Complications in Craniofacial Surgery: How to Treat and to Avoid Them. 4th Congress of Plastic Surgeons of Armenia and 5th of Georgia 22.
6. Sulamanidze M, Adamyan A, Sulamanidze G, Sultanova N, Nishnianidze G (2002) Simultaneous aesthetic interventions on the face for rhinoplasty. Annals of Plastic, Reconstructive and Aesthetic Surgery 1: 7-20.

7. Sulamanidze M, Adamyan A, Sulamanidze G, Nishnianidze G (2004) Aesthetic surgery of the wide nose. Annals of Plastic, Reconstructive and Aesthetic Surgery 3: 6-17.

8. Sulamanidze M, Adamyan A, Sulamanidze G (2009) Aesthetic Rhinoplasty in Rhinomegaly. Own Experience. 11-th ESPRAS Congress. 347.

9. Sulamanidze M, Adamyan A, Sulamanidze G, Nishnianidze G (2011) Aesthetic surgery of the wide nose. Our approaches. 34th Annual Conference of the European Academy of Facial Plastic Surgery. p 6 .

10. Gryskiewicz JM (2002) The "iatrogenic-hanging columella": preserving columellar contour after tip retroprojection. Plast Reconstr Surg 110: 272-277. [Crossref]

11. Bafaquen SA, Quattan MM (2000) Simultaneous open Rhinoplasty and Alar Bas excision: is there a problem with the blood supply of the nasal tip and columellar skin? Plast Reconstr Surg 105: 344-347.

12. Marino A (1966) Considerazioni Sulla "Rinotomia Esterna Per Via Dissimulata" Goumain E Planes. Il Valsalva XLII: 3-11.

Copyright: $(02016$ Sulamanidze M. This is an open-access article distributed under the terms of the Creative Commons Attribution License, which permits unrestricted use, distribution, and reproduction in any medium, provided the original author and source are credited. 